\title{
Molecular identification of Mycobacterium avium subspecies paratuberculosis in an Italian patient with Hashimoto's thyroiditis and Melkersson-Rosenthal syndrome
}

Mycobacterium avium subspecies paratuberculosis (MAP) causes Johne's disease, a chronic granulomatous intestinal condition that affects ruminants, including cattle, sheep, goats and farmed deer (Naser et al., 2004). Water and milk supplies have both been suggested as vehicles of MAP transmission between cattle and humans (Pickup et al., 2006; Groenendaal \& Zagmutt, 2008). Milk may be contaminated directly within the udder or indirectly as a result of faecal contamination (Giese \& Ahrens, 2000).

This bacterium has attracted considerable interest owing to the rapidly growing body of scientific evidence suggesting similarities between Johne's disease in ruminants and Crohn's disease in humans, which has led to speculation that MAP might be one of the causative agents in Crohn's disease (Naser et al., 2004).

However, because of the complex nature of human Crohn's disease, as well as the conflicting experimental evidence, a definitive link between MAP and Crohn's disease can neither be confirmed nor excluded at present. Some authors believe there is no evidence that a single pathogen, including MAP, is involved in the pathogenesis of inflammatory bowel diseases (Packey \& Sartor, 2009), while others have reported that MAP may asymptomatically colonize apparently healthy individuals (Juste et al., 2008). Therefore, no causal link has been scientifically established between MAP and Crohn's disease, although it is important to note that much evidence supports the possibility of such a relationship. The MAP debate has gathered momentum in recent years because of the more frequent detection of MAP in the blood and tissues of Crohn's disease patients as compared with controls. The over-representation of MAP DNA in Crohn's disease patients suggests a probable role for MAP in the aetiology of this pathological condition (Bentley et al., 2008).

There is still much to be learned about MAP and the diseases it may cause in humans. Recent findings by Sechi and colleagues and by Dow link diabetes to Crohn's disease, since they found MAP bacteraemia involved with autoimmune diabetes (Sechi et al., 2005, 2008; Dow, 2008). Consumption of cows' milk early in life is a recognized risk factor in the development of these diseases, and environmental micro-organisms are thought to trigger autoimmune responses in genetically susceptible individuals (Dow, 2008).

Recently, we described the case of a 52year-old woman with non-caseating granulomatous inflammation in the oral and facial regions, accompanied by facial nerve palsy, diagnosed as MelkerssonRosenthal syndrome (MRS), a condition of unknown aetiology. In addition, the patient has suffered from Hashimoto's thyroiditis for the previous 4 years as confirmed by an endocrinological investigation and laboratory tests (Scagliusi et al., 2008).

In view of the literature supporting the involvement of MAP in autoimmune disease (Sechi et al., 2005, 2008; Dow, 2008), and a possible autoimmune aetiology for MRS (Gottwald, 1981), an analysis of the patient's family and personal history and lifestyle, led us to hypothesize the presence of a MAP infection. The patient had lived since childhood on a farm with cattle, in an Italian region where MAP is widespread in cattle-breeding farms. For a long period of her life, she drank cows' milk produced directly at her farm and her diet was still largely based on dairy products. In addition, to the above-described clinical picture she had suffered for many years from bowel disorders. For these reasons, we performed blood tests for the presence of MAP.

RT-PCR was used to reveal the presence of viable MAP using mRNA extracted from peripheral blood mononuclear cells (PBMCs) and amplifying IS900 sequences unique to MAP (Green et al., 1989). We investigated four samples collected at 1 month intervals. A $20 \mathrm{ml}$ aliquot of the patient's peripheral blood was transferred into tubes containing EDTA (disodium salt) anticoagulant. The samples were immediately processed to obtain PBMCs. Samples were diluted with an equal volume of PBS and overlaid on FicollPaque solution (Amersham Biosciences). The subsequent Ficoll gradient centrifugation was performed at room temperature. The PBMC interphase was transferred to $30 \mathrm{ml} \mathrm{PBS}$ and centrifuged (500 $\mathrm{g}, 10 \mathrm{~min}$ ). The supernatant was discarded and cell pellets were resuspended in $20 \mathrm{ml}$ PBS. Cells were counted with trypan blue and centrifuged $(500 \mathrm{~g}$, $5 \mathrm{~min}$ ). After removing the supernatant, total RNA was extracted from cells using TRIzol reagent (Invitrogen) ( $1 \mathrm{ml}$ TRIzol for $1 \times 10^{7}$ cells). Cells were lysed by repetitive pipetting and incubated for $5 \mathrm{~min}$ at ambient temperature to permit complete dissociation of nucleoprotein complexes. We used DNase I [10 $\mu$ l DNase I (ml sample) $)^{-1}$ at $37{ }^{\circ} \mathrm{C}$ for $30 \mathrm{~min}$ ] (Applied Biosystems) to remove contaminating DNA. DNase I was removed from the reaction prior to PCR by the use of heat $\left(70{ }^{\circ} \mathrm{C}\right.$ for $\left.5 \mathrm{~min}\right)$. DNase-treated RNA $(2 \mu \mathrm{g})$ was reverse transcribed to cDNA using the SuperScript first-strand cDNA synthesis kit (Invitrogen), according to the manufacturer's instructions. A primary and a secondary round of PCR were done. Oligonucleotide primers were derived from the DNA insertion sequence IS 900. The primers P90 (5' -GTTCGGGGCCGTCGCTTAGG-3') and P91 (5'-GAGGTC- 
GATCGCCCACGTTGA-3') were used for the first round to amplify a unique $398 \mathrm{bp}$ fragment of the IS900 gene. Sensitivity and specificity for the amplified MAP DNA fragment were achieved by the use of AV1 (5'-ATGTGGTTGCTGTGTTGGATGG$\left.3^{\prime}\right)$ and AV2 (5'-CCGCCGCAATCAACTCCAG-3) oligonucleotide primers in the second round to reamplify a $298 \mathrm{bp}$ internal nucleotide sequence of the $398 \mathrm{bp}$ template. The PCR mixture consisted of $40 \mu \mathrm{l} \mathrm{PCR}$ buffer, $5 \mathrm{mM} \mathrm{MgCl}_{2}, 0.2 \mathrm{mM}$ dNTP, $6 \%$ DMSO, $2 \mu \mathrm{M}$ primers, and 2.5 U Platinum Taq polymerase (Invitrogen) and $10 \mu \mathrm{l}$ DNA template. The PCR mixture in the second round of the PCR was the same, except that $5 \mu$ PCR product from the first round was used as a template and the AV1 and AV2

oligonucleotide primers were substituted. The PCR cycling conditions were: $95{ }^{\circ} \mathrm{C}$ for $5 \mathrm{~min}, 34$ cycles of $95{ }^{\circ} \mathrm{C}$ for $1 \mathrm{~min}$, $58{ }^{\circ} \mathrm{C}$ for $1.5 \mathrm{~min}$ and $72{ }^{\circ} \mathrm{C}$ for $1.5 \mathrm{~min}$, and a final extension of $10 \mathrm{~min}$ at $72{ }^{\circ} \mathrm{C}$. The amplification product size was assessed on a $2 \%$ agarose gel. The positive MAP control was ATCC 19698 DNA, and a band co-migrating with the ATCC 19698 DNA at the predicted amplicon size of 298 bp was considered positive. As negative control a MAP-negative subject was used. Bands obtained from four samples were purified and sequenced (Primm). The sequence identity of the final $298 \mathrm{bp}$ amplicon was compared with the GenBank accession number EF514830 sequence for MAP IS900 using the International Nucleotide Sequence Database (National Institutes of Health - International Nucleotide Sequence Database Collaboration, http://www.ncbi.nlm.nih. gov) and sequence alignment analyses. The gel of PCR products (Fig. 1) showed a band that co-migrated with the positive control at the predicted $298 \mathrm{bp}$ amplicon size. The sequenced DNA obtained from four samples showed $100 \%$ identity with MAP IS900.

There is current evidence that a percentage of healthy individuals have MAP DNA in their blood, the significance of which remains to be determined (Collins et al., 2000; Juste et al., 2008). However, there are specific states of immune dysfunction or genetic predisposition that could promote mycobacterial infections. Identification of MAP in the blood of this Hashimoto's

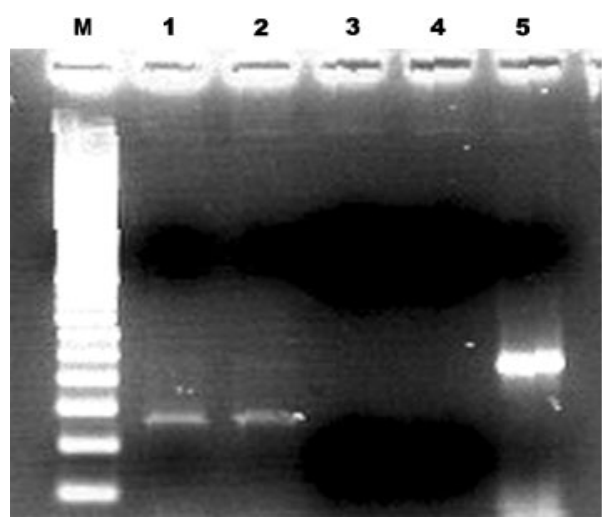

Fig. 1. Agarose electrophoresis gel of amplified IS900 fragments. M, molecular marker; lane 1, MAP-positive control; lane 2, patient sample; lane 3, distilled water negative control; lane 4, MAP-negative control subject; 5, RT-PCR of internal control GADPH.

thyroiditis patient could be more than a coincidence. It is common knowledge that human pathogens often express proteins with a high antigenic potential and strong homologies with human proteins.

Evolutionary pressures based upon the necessity to escape host-specific immune responses may have determined this phenomenon, known as 'molecular mimicry'. It is reasonable to assume that certain individuals can develop abnormal immune responses upon contact with an antigen that mimics a self-protein. The human heat-shock protein Hsp60, for example, with a high degree of homology with Hsp65 of MAP, shares a sequence homology with a wide range of autoantigens including those of Hashimoto's thyroiditis (Jones et al., 1993). Furthermore, recent findings report a possible Mycobacterium tuberculosis aetiology for MRS (Apaydin et al., 2000).

To the best of our knowledge, this report is the first observation of a MAP infection in a patient with MRS. The findings are consistent with early exposure to dietary cows' milk and underline the possibility that milk from cattle with Johne's disease could be a potential transmission vehicle for MAP to humans.

\section{Massimo D'Amore, ${ }^{1}$ Sabrina Lisi, ${ }^{2}$ Margherita Sisto, ${ }^{2}$ Liana Cucci $^{2}$ and C. Thomas Dow ${ }^{3}$}

${ }^{1}$ Department of Internal Medicine and Public Medicine, Section of
Rheumatology, University of Bari, Piazza G. Cesare 1, I-70124 Bari, Italy

${ }^{2}$ Department of Human Anatomy and Histology, University of Bari, Piazza

G. Cesare 1, I-70124 Bari, Italy

${ }^{3}$ Department of Ophthalmology, University of Wisconsin, Madison, WI, USA

Correspondence: Sabrina Lisi (s.lisi@anatomia.uniba.it)

Apaydin, R., Bilen, N., Bayramgürler, D. Efendi, H. \& Vahaboglu, H. (2000). Detection of Mycobacterium tuberculosis DNA in a patient with Melkersson-Rosenthal syndrome using polymerase chain reaction. Br J Dermatol 142, 1251-1252.

Bentley, R. W., Keenan, J. I., Gearry, R. B., Kennedy, M. A., Barclay, M. L. \& Roberts, R. L. (2008). Incidence of Mycobacterium avium subspecies paratuberculosis in a populationbased cohort of patients with Crohn's disease and control subjects. Am J Gastroenterol 103, 1168-1172.

Collins, M. T., Lisby, G., Moser, C., Chicks, D., Christensen, S., Reichelderfer, M., Høiby, N., Harms, B. A., Thomsen, O. O. \& other authors (2000). Results of multiple diagnostic tests for Mycobacterium avium subsp. paratuberculosis in patients with inflammatory bowel disease and in controls. J Clin Microbiol 38, 4373-4381.

Dow, C. T. (2008). Cows, Crohn's and more: is Mycobacterium paratuberculosis a superantigen? Med Hypotheses 71, 858-861.

Giese, S. B. \& Ahrens, P. (2000). Detection of Mycobacterium avium subsp. paratuberculosis in milk from clinically affected cows by PCR and culture. Vet Microbiol 77, 291-297.

Gottwald, W. (1981). Melkersson-Rosenthal syndrome. 2: Diagnosis, differential diagnosis, 
course, prognosis, neuropathology, therapy. Fortschr Med 99, 326-330 (in German).

Green, E. P., Tizard, M. L., Moss, M. T. Thompson, J., Winterbourne, D. J., McFadden, J. J. \& Hermon-Taylor, J. (1989). Sequence and characteristics of IS900, an insertion element identified in a human Crohn's disease isolate of Mycobacterium paratuberculosis. Nucleic Acids Res 17, 9063-9073.

Groenendaal, H. \& Zagmutt, F. J. (2008). Scenario analysis of changes in consumption of dairy products caused by a hypothetical causal link between Mycobacterium avium subspecies paratuberculosis and Crohn's disease. J Dairy Sci 91, 3245-3258.

Jones, D. B., Coulson, A. F. \& Duff, G. W. (1993). Sequence homologies between Hsp60 and autoantigens. Immunol Today 14, 115-118.

Juste, R. A., Elguezabal, N., Garrido, J. M., Pavon, A., Geijo, M. V., Sevilla, I., Cabriada, J. L., Tejada, A., García-Campos, F. \& other authors
(2008). On the prevalence of Mycobacterium avium subspecies paratuberculosis DNA in the blood of healthy individuals and patients with inflammatory bowel disease. PLoS One 3, e2537.

Naser, S. A., Ghobrial, G., Romero, C. \& Valentine, J. F. (2004). Culture of Mycobacterium avium subspecies paratuberculosis from the blood of patients with Crohn's disease. Lancet 364, 1039-1044.

Packey, C. D. \& Sartor, R. B. (2009).

Commensal bacteria, traditional and opportunistic pathogens, dysbiosis and bacterial killing in inflammatory bowel diseases. Curr Opin Infect Dis 22, 292-301.

Pickup, R. W., Rhodes, G., Bull, T. J., Arnott, S., Sidi-Boumedine, K., Hurley, M. \& HermonTaylor, J. (2006). Mycobacterium avium subsp. paratuberculosis in lake catchments, in river water abstracted for domestic use, and in effluent from domestic sewage treatment works: diverse opportunities for environmental cycling and human exposure. Appl Environ Microbiol 72, 4067-4077.

Scagliusi, P., Sisto, M., Lisi, S., Lazzari, A. \&

D'Amore, M. (2008). Hashimoto's thyroiditis in Melkersson-Rosenthal syndrome patient: casual association or related diseases? Panminerva Med 50, 255-257.

Sechi, L. A., Scanu, A. M., Molicotti, P., Cannas, S., Mura, M., Dettori, G., Fadda, G. \& Zanetti, S. (2005). Detection and isolation of Mycobacterium avium subspecies paratuberculosis from intestinal mucosal biopsies of patients with and without Crohn's disease in Sardinia. Am J Gastroenterol 100, 1529-1536.

Sechi, L. A., Paccagnini, D., Salza, S., Pacifico, A., Ahmed, N. \& Zanetti, S. (2008). Mycobacterium avium subspecies paratuberculosis bacteremia in type 1 diabetes mellitus: an infectious trigger? Clin Infect Dis 46, 148-149. 